\title{
Economic arguments for representative sampling
}

\author{
Special Section Editor: Kim H. Esbensen
}

\begin{abstract}
Abel Arkenbout, ${ }^{a}$ Stéphane Brochot, ${ }^{b}$ Trevor Bruce, ${ }^{\mathrm{c}}$ Pedro Carrasco, Pablo Carrasco, Philippe Davin, ${ }^{d}$ Quentin Dehaine, ${ }^{\mathrm{e}}$ Oscar Dominguez, ${ }^{\mathrm{f}}$ Simon C. Dominy, ${ }^{\mathrm{g}}$ Kim H. Esbensen, ${ }^{\mathrm{h}}$ Dominique François-Bongarçon, ${ }^{i}$ Melissa Gouws, ${ }^{j}$ Ralph J. Holmes, ${ }^{k}$ Li Huachang,' Eduardo Jara, Martin Lischka, ${ }^{\text {m}}$ Geoff Lyman, ${ }^{n}$ Zhu Mingwei, ${ }^{\prime}$ Pentti Minkkinen, ${ }^{\circ}$ Richard C.A. Minnitt, ${ }^{\mathrm{p}}$ Claudia Paoletti, ${ }^{q}$ Christopher Robben, ${ }^{r}$ Rodolfo J. Romañach, ${ }^{\text {s }}$ Elke Thisted ${ }^{\mathrm{t}}$ and D. Aldwin Vogel ${ }^{\mathrm{u}}$
\end{abstract}

ahttps://toxicowatch.wixsite.com/toxicowatch

bManaging director, Caspeo. www.caspeo.net

${ }^{\mathrm{C} F L S m i d t h, ~ B o k s b u r g}$ East, 1459, South Africa

¿Sales Manager, Bulk Solids DPT, Iteca Socadei, Aix-en-Provence, France

${ }^{\text {e}}$ Circular Economy Solutions Unit, Geological Survey of Finland, PO Box 96, 02151 Espoo, Finland

${ }^{f} G$ lobal Principal Geoscientist QAQC, Technical Centre of Excellence, BHP, Perth, Australia

${ }^{8}$ Camborne School of Mines, Cornwall, UK and Novo Resources Corporation, Perth, Western Australia

hIndependent researcher, consultant, owner, KHE Consulting, Copenhagen, Denmark. kheconsult.com

'Agoratek International Consultants, Inc.

'InnoVenton, Nelson Mandela University, Gqeberha (Port Elizabeth), South Africa

kHonorary Fellow, Mineral Resources, CSIRO, Private Bag 10, Clayton South, Vic, 3169, Australia

'BGRIMM MTC Technology Co. Ltd, China

mHERZOG Maschinenfabrik GmbH \&Co. KG, Auf dem Gehren 1, 49086 Osnabrück, Germany

"Materials Sampling \& Consulting

oPresident, Senior Consultant, SIRPEKA Oy; Professor emeritus, Lappeenranta University of Technology, Finland

PVisiting Emeritus Professor, University of the Witwatersrand, Johannesburg, South Africa

aProgram Manager, Transformation Unit - TS, European Food Safety Authority, Via Carlo Magno 1/A, 43100 Parma, Italy 'SIX-S GmbH, Hinter der Kirche 1A, 22880 Wedel, Germany

sUniversity of Puerto Rico, Mayagüez Campus, Puerto Rico

${ }^{\mathrm{t}} \mathrm{Glencore}$ Nikkelverk AS; Head of organisational committee for WCSB 10

uTechnical \& Quality Director, Commodities Global Service Lines, Bureau Veritas, Rotterdam, the Netherlands

"A loss of a money is a certainty if the responsible entities have not made sure that all sampling and analysis performed to produce decision making information is representative. It is as simple as that..."

A complaint has recently surfaced from the more business-oriented world that the sampling community mainly furthers "technological" arguments for engaging

DOI: $10.1255 /$ sew.2021.a30

(C) 2021 The Authors

Published under a Creative Commons BY-NC-ND licence

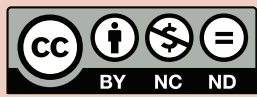

with proper sampling: "the Theory of Sampling (TOS) is all very fine, but it doesn't sell many tickets where it really counts, at CEO levels or higher (board of directors, investors, bankers). At this level decision-makers do not have the time, or cannot (or will not) make the effort to understand a theory." While seriously flawed and superficial, this opinion is nevertheless widespread, and especially so in those top-level decision-making circles where the sampling community would dearly like to make a greater impact! So, sensing a marketing scoop, the Column Editor has asked a distinguished group of TOS illuminati to address this economics issue head on. What follows below is the definitive collection of "business arguments for the TOS", writ large. So, read this column carefully-and forever hold your peace!

\section{The challenge}

What is the best way to engage anyone who has never given much thought to why representative sampling is 


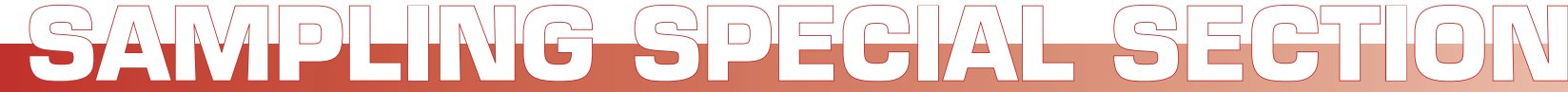

critically important for most endeavours in science, technology, industry, commerce, trade and society? This is in fact a standard topic within the sampling community itself: "What is the best way to promote the TOS-not only as a theory, but as a practical tool to help customers? Indeed, as a critical tool that will have a significant impact on the bottom line!"
The latter casts the issue into a rather direct format: "How to sell TOS-compliant equipment, system solutions, consulting and audit services to customers with only little, or no, familiarity with the need for proper sampling?"

Ever since the inception of the TOS (in 1950) there has been a healthy discussion about this issue, about which opinions are often sharply divided. There are traditionally two types of answers: the business argument "You stand to lose a lot of money if you don't..."; or the technical argument: "You need to understand these critical aspects of TOS, or else...". 